\title{
Profile of subjective quality of life and its correlates in a nation-wide sample of high school students in an Arab setting using the WHOQOL-Bref
}

\author{
Ghenaim A Al-Fayez ${ }^{1}$ and Jude U Ohaeri ${ }^{*}$
}

\begin{abstract}
Background: The upsurge of interest in the quality of life (QOL) of children is in line with the 1989 Convention on the Rights of the Child, which stressed the child's right to adequate circumstances for physical, mental, and social development. The study's objectives were to: (i) highlight how satisfied Kuwaiti high school students were with life circumstances as in the WHOQOL-Bref; (ii) assess the prevalence of at risk status for impaired QOL and establish the QOL domain normative values; and (iii) examine the relationship of QOL with personal, parental, and socioenvironmental factors.
\end{abstract}

Method: A nation-wide sample of students in senior classes in government high schools ( $\mathrm{N}=4467,48.6 \%$ boys; aged 14-23 years) completed questionnaires that included the WHOQOL-Bref.

Results: Using Cummins' norm of 70\% - 80\%, we found that, as a group, they barely achieved the well-being threshold score for physical health (70\%), social relations (72.8\%), environment (70.8\%) and general facet (70.2\%), but not for psychological health (61.9\%). These scores were lower than those reported from other countries. Using the recommended cut-off of $<1 S D$ of population mean, the prevalence of at risk status for impaired QOL was 12.9\% - 18.8\% (population age-adjusted: 15.9\% - 21.1\%). In all domains, boys had significantly higher QOL than girls, mediated by anxiety/depression; while the younger ones had significantly higher QOL $(p<0.001)$, mediated by difficulty with studies and social relations. Although poorer QOL was significantly associated with parental divorce and father's low socio-economic status, the most important predictors of poorer QOL were perception of poor emotional relationship between the parents, poor self-esteem and difficulty with studies.

Conclusion: Poorer QOL seemed to reflect a circumstance of social disadvantage and poor psychosocial well-being in which girls fared worse than boys. The findings indicate that programs that address parental harmony and school programs that promote study-friendly atmospheres could help to improve psychosocial well-being. The application of QOL as a school population health measure may facilitate risk assessment and the tracking of health status.

Keywords: Quality of life students, Arab, gender, age, parents

\section{Background}

The upsurge of interest in the quality of life (QOL) of children in general population samples is in line with the 1989 Convention on the Rights of the Child, which stressed the child's right to adequate circumstances of physical, mental, and social development $[1,2]$. While most of the general population studies have emanated

\footnotetext{
* Correspondence: judeohaeri@hotmail.com

${ }^{2}$ Department of Psychiatry, Psychological Medicine Hospital, Gamal Abdul Naser Road, P.O. Box 4081, Safat, Kuwait

Full list of author information is available at the end of the article
}

from the western world [3-11], a few have come from Asia [12-14], South America [15] and Iran [16]. There are no such reports from the Arab world. The lone report on QOL for students from an Arab country was based on a convenience sample of 224 college students and was focused on the relationship with intensity of religiosity [17].

Although various authors have recommended that the assessment of QOL among adolescents should include contextual variables that are not generally regarded as health-related (e.g., satisfaction with family and peer

\section{() Biomed Central}


relationships and family income) [5,18-23], most reports have been based on health-related quality of life (HRQOL) measures [reviewed, [1,24]]. Only a few have used instruments that attempt to cover the broader issues of QOL $[7,11,13]$, including a modification of the WHO Quality of Life Instrument (WHOQOLI) [13,25]. QOL measures that focus on the construct of HRQOL have been criticized on the grounds that their narrow focus on the impact of health conditions on physical, psychological and social functioning implies that full health equates to maximum QOL [24,26-29]. In a critique of six definitions of QOL, it was suggested that defining QOL in terms of life satisfaction is the most appropriate [29]. Instruments for pediatric QOL assessment should have conceptually strong underpinnings[24].

It is important to assess the QOL of adolescents and young adults of school age using instruments that include contextual variables, because the vast majority are healthy [30]; and since QOL is sensitive to distress in various domains of living [31], the data can help to provide information beyond symptoms, to identify an otherwise undetectable high risk group for problems [32]. For such a population, reliance on the traditional measures of health could lead to under-identification of psychosocial problems, "the new hidden morbidity" $[5,33]$. In view of the above considerations, we have used the short version of the WHOQOLI (the WHOQOL-Bref) to assess the subjective QOL of a nation wide sample of senior high school students; first, because the items emphasize satisfaction with life circumstances [24,29], and the domains encompass health-related and contextual issues that have been found to be important for adolescents [19,34]. Second, the Arabic translation of the WHOQOL-Bref has been shown to have satisfactory reliability and validity indices in general population and clinical samples $[35,36]$. Third, the WHOQOL-Bref was simultaneously developed in diverse cultures, thus overcoming the usual controversy over the problem of applying a questionnaire articulated in one culture in a different culture [25,37]. It is noteworthy that the original validation sample for the WHOQOL-Bref [25] included adolescents (aged 12 - $19 \mathrm{yrs}$ ). In other words, the WHOQOL-Bref is judged to be appropriate for the age group that we studied. We have done the assessment using the model described by Jirojanakul et al [13]. In this model, personal and parental background factors, general health factors and socio-environment factors are all significantly associated with QOL.

This is based on the evidence that personal background factors have been found to be associated with QOL. Thus, while reports of adolescent samples (>12 years) consistently found that poorer QOL was significantly associated with female gender and older age [3,5,16,38-41], the reports that involved children who were less than 12 years of age either found that there were no significant gender differences [42], or that the girls had significantly better QOL $[13,14,43]$. In addition, poorer QOL was associated with poor physical health, psychic distress, and low selfesteem [7-9]. Of the parental factors, the consistent findings are that, poorer QOL was associated with parental low socio-economic status, low educational attainment, and divorce [3-5,7-10,15,44,45]. Of the socio-environmental factors, parental stress and the quality of emotional relationship between the parents were found to have longterm implications for the child's well-being $[6,9,46,47]$. Interestingly, children can reliably report on the quality of emotional relationship between their parents, while parents can predict children's response about parental relationship [46,48]. Furthermore, better QOL was significantly associated with easy access to health service, lack of feeling of difficulty at school, and connectedness with school $[5,8,49]$. It has been suggested that older adolescents tend to have poorer QOL, possibly because they are exposed to greater social demands and stresses, such as increased academic, emotional and other social pressures, so that they tend to have relatively more difficult life situations to contend with, in comparison with the younger ones [19].

At the conceptual level, a notable problem with QOL data is the interpretation of what the data mean. This problem concerns the issues of a cut-off score for poorer QOL or the identification of subjects "at risk status for impaired QOL" [30], and the clinical significance of the scores [50,51]. An important helpful step in this regard is the use of scales whose domains are aggregated into percentage maximum score of 0 to 100 (i.e., \% scale maximum or \% SM method). In a review of several studies from the western world, it was found that the average score for healthy populations tended to be in the range of $70-80 \%$ SM [22,52]. Accordingly, it was suggested that subjective well-being could be operating within a psychological homeostatic regulation system (like body temperature) that is represented by a score of $70 \%-80 \%$ of scale maximum for QOL instruments [22]. It appears that this recommendation is relevant for pediatric populations, too. For example, in a review of the Pediatric Quality of Life (PedsQOL) [4] domain scores of six studies in large samples of school children from the western world, it was shown that in five of them, the average scores for the domains of QOL (using child ratings) ranged from $72.9 \%$ to $91.1 \%$ [9]. In the sixth study, the children had a mean total PedsQOL score of 67.2, which the authors considered to be relatively low [8]. Other studies from Finland $(75.4 \%-85.0 \%)$ [38] and the USA $(78.2 \%$ $84.0 \%$ ) [30] had similar findings. This is supported by similar data from non-western countries, such as Korea 
(82.6\% - 93.5\%) [12], Brazil (73.0\% - 93.1\%) [15], and Iran $(71.7 \%-90.9 \%)$ [16]. For another questionnaire, the Generic Children's Quality of Life Measure, a UK study reported 72.7\% - 75.3\% [11]. Using another yardstick, it has been suggested that a QOL domain score of 1 standard deviation $(1 S D)$ below the population mean would probably help to identify subjects at risk for impaired QOL $[9,30,53]$, because such scores represent scale scores similar to those of children with severe chronic health conditions [30].

The design of our study was guided by the issues highlighted above. With regard to those issues, the Kuwaiti perspective is important because it adds the contribution from a country where, for nationals, there is an effective national social welfare system, health care services are free and easily accessible; and the conservative Muslim culture, with traditional gender roles and sexual segregation, prevails. It has been suggested that QOL is context-specific [13].

\section{Objectives}

The specific objectives of the study were to:

(i) highlight how satisfied Kuwaiti senior high school students were with life circumstances as in the WHOQOLBref; (ii) estimate the prevalence of at risk status for impaired QOL, and establish the QOL domain score normative values, in comparison with the international data [25]; (iii) examine the relationship of QOL with personal factors (socio-demographic variables), general health factors (subjects' perception of being currently ill, and their scores on scales for anxiety, depression and self-esteem); parental factors (parental employment, educational and marital status); and socio-environment factors (perceived difficulty with studies and social relationships, and perceived quality of emotional relationship between the parents).

We hypothesized that, in view of the widely noted importance of parental material well-being and health access:

- Kuwaiti students would be generally satisfied with their circumstances of living,

- and their average QOL domain scores would be high, in comparison with the international data.

- In view of the robust findings in the literature, however, poorer QOL would be significantly associated with female gender, older age, high scores on anxiety and depression, low self-esteem and poor perception of the emotional relationship between the parents.

\section{Methods}

\section{Participants and setting}

Kuwait is an oil - rich Arab country, located in the Arabian Gulf. Of the total 3.4 million population, Kuwaiti nationals make up about 1.1 million (48.9\% male, $51.1 \%$ female) (2007 census). There are six administrative districts or governorates. About $97 \%$ live in urban areas, and the unemployment rate is $2.3 \%$ (2004 estimate). According to the 2007 census data from the Kuwait Public Authority for Civil Information (PACI), those aged 14 - 23 years (our sample age range) (212144) constituted $20.4 \%$ of nationals (50.5\% male, $49.5 \%$ female). Our sample size was guided by the recommendation of the International Quality of Life Assessment (IQOLA) project researchers, that the sample size for general population norming should be 2500 - 3000 [54]. This would allow for comparison of scale scores by gender and 10 - year age groups.

The study took place in Kuwaiti government secondary schools in all the governorates. All such schools are sexually segregated. Accordingly, the sampling strategy was aimed at representing the three types of schools, viz: boys', girls', and the credit-hour system (i.e., senior high schools where students have the option to choose three subjects per session). The focus was on students in the senior classes, consisting of grades (class years) 10,11 , and 12 . This is because the questionnaires are self - rated and there was need to focus on an age group that would not have difficulty understanding and completing them. In 2006/7, a nationwide sample of 4467 senior high school students (mean age 16.9, $S D=$ 1.2 yrs, range $=14-23$ ) in Kuwaiti government secondary schools was studied, with adequate representation of the governorates and gender ( $48.6 \%$ boys). The participants hailed predominantly from fairly large, stable and harmonious family homes $(83.1 \%$ rated parental relationship as good/excellent; $85.1 \%$ of parents lived together, and average sibling size was 6.3). Most fathers (73.3\%) were gainfully employed. Of the 4442 (99.4\%) who stated their nationality, 3771 (87.3\%) were Kuwaitis, 69 (1.6\%) were stateless citizens ("bedoons"), and 458 (10.3\%) were from other Arab countries, especially the Arabian Gulf states.

\section{Procedure}

First, a list of all the government secondary schools was obtained from the Ministry of Education. Six schools were randomly selected from each of the six governorates (total, 36 schools), viz: two each from boys', girls' and credit-hour system. From each selected school, two classes each from grades 10 and 11, and one class from grade 12 were randomly selected, in order to proportionately represent the number of classes in each grade.

\section{Ethical considerations}

The study was carried out in compliance with the Helsinki Declaration. Hence, the protocol for all aspects of the study, including the pilot testing of the questionnaires, was 
approved by the institutional review boards of the Kuwait Ministry of Education and the Kuwait Society for the Advancement of Arab Children (KSAAC). Thereafter, the Principal of each selected school was approached for approval and for the cooperation of the school's psychologists. At the preliminary stage of the study, the research team hosted the psychologists of the selected schools at meetings facilitated by the Ministry of Education.

A few days after explaining the objectives of the study to the selected classes, the schools' psychologists and class prefects chose dates and times convenient to the study schedule. In the few days between explaining the nature of the study and the completion of the questionnaires, the students were requested to inform their parents about the study, in case any parents would refuse. It was emphasized that refusal to participate would not lead to any form of punishment. In the Kuwaiti culture, this method of obtaining informed consent from the Ministry of Education, the KSAAC, and the school principals, is deemed sufficiently ethical for such a study. Moreover, the questionnaires were completed in class, under the supervision of school psychologists whom the students and their parents were familiar with. There were no refusals by parents and students. In order to ensure adequate supervision and explain possibly difficult items, the school psychologists stayed with them in class while the students completed the questionnaires, anonymously. All students in the selected classes agreed to complete the questionnaires. Although we did not record the number of students who were not present in school for the selected classes on the days of the study, our impression was that this number was probably very small and not obvious to the school psychologists.

\section{Pilot testing of the questionnaires}

Before the commencement of the study, the questionnaires were translated into Arabic by the method of back - translation. The research team critically examined the instruments and presented them to senior mental health workers to examine the face validity of the contents. Thereafter, the modified version, as detailed below, was pilot tested among students ( 50 boys and 50 girls), from two schools that were not part of the main study, using the same methodology as described above. Test - retest reliability was assessed by analyzing the responses of 55 subjects (from the 100) who volunteered to complete the final questionnaires twice in a four week period.

\section{Operational definitions}

We accepted the WHO definition of QOL as individuals' perception of life in the context of the culture and value system in which they live and in relation to their goals, expectations, standards and concerns [25].
This was the conceptual framework for articulating the WHOQOL Instrument [34]. It has also been adopted as the conceptual framework for a measure of QOL for children [55]. Our focus was on subjective QOL, as distinct from objective QOL [56].

We defined subjects' satisfaction as the level of positive appreciation for each item of the WHOQOL-Bref [29]. That is, we used the idea of satisfaction for an item as a rating of more than average or neutral point $[57,58]$, which in the case of the WHOQOL-Bref varies (according to the wording of the item) as: good/very good; mostly/completely; or satisfied/very satisfied. Hence, we quantified the group's satisfaction with each item as at least $50 \%$ of respondents in the group rating the item as good/very good; dissatisfaction $(<50 \%)$; bare satisfaction (50 - 65\%); moderate satisfaction (66 - 74\%); and highest satisfaction $(\geq 75 \%)[56]$.

\section{The WHOQOL - Bref}

This is a 26 - item self - administered generic questionnaire, being a short version of the WHOQOL - 100 scale [25]. The response options range from 1 (very dissatisfied/very poor) to 5 (very satisfied/very good). It emphasizes the subjective responses rather than objective life conditions, with assessment made over the preceding two weeks. It consists of domains (or dimensions) and a facet (or sub - domain). The items on "overall rating of QOL" (OQOL) and subjective satisfaction with health, are not included in the domains, but are used to constitute the general facet on OQOL and general health (general facet). The more popular model for interpreting the scores has four domains, namely, physical health (seven items), psychological health (six items), social relations (three items) and environment (eight items). Our analysis was based on this model.

The domain scores of the WHOQOL-Bref can be computed in three ways. The first is a summation of the raw scores of the constituent items. The second and third ways consist of transforming the raw scores. In the second way, the raw scores are transformed into scores that range from 4-20, to be in line with the WHOQL -100 Instrument. The third way, which is the percentage scale maximum (\% SM) is a standardized conversion of Likert scale data projected onto a 0-100 scale. The WHOQOL Group has provided guidelines for these conversions [59]. The value of the later transformed score method (i.e., \% SM) is that it can be used for making comparison with other scales [52].

There was need to modify the framing of some items of the WHOQOL-Bref in order to make them suitable to the circumstances of school age persons in this culture. First, the WHOQOL has no item on "school". Second, high school students in this culture are entirely dependent on their parents for financial and transportation 
needs. Third, by law, they are prohibited from engaging in romantic sexual activities. Accordingly, following the methods in the literature [1,23], we modified the following items of the WHOQOL-Bref to read thus:

(a) Item 12, on money: "How satisfied are you with the money available in your family for your care"; (b) Item 18: "How satisfied are you with your ability to do your school work"; (c) Item 21: "How satisfied are you with your sexual feelings"; (d) Item 24: "How satisfied are you with access to health services"; (e) Item 25: "How satisfied are you with the transportation facilities available to you."

In order to determine whether the pattern of response to the five modified items differed from the pattern of response to the other items, we examined the floor effects (i.e. \% of subjects who rated themselves as "very dissatisfied" with each item) and ceiling effects (i.e. \% of subjects who rated themselves as "very satisfied" with each item) for the five items, in comparison with those of the other items, and the WHO validating data [25]. Using the data for all participants $(\mathrm{N}=4467)$, we found that the floor effect for the five modified items $(2.2 \%$ $8.7 \%)$ was similar to the range for the other items $(1.6 \%$ - $8.1 \%)$, and the WHO data $(1.7 \%-8.8 \%)$. Also, the ceiling effect for the five items $(17.6 \%-53.9 \%)$ was within the range for the other items $(13.1 \%-59.2 \%)$, and comparable with the WHO data $(10.1 \%-35.2 \%)$.

Test - retest reliability (intra class correlation coefficient) for 39 subjects with full data for the retest exercise at the preliminary stage of the study was $0.95(95 \%$ C. I. $=0.92-0.97)$. For the entire population of participants $(\mathrm{N}=4467)$, the alpha coefficient (internal consistency) for the WHOQOL-Bref was 0.91 .

QOL domain scores (range 0 - 100\%) were generated by organizing the items into the four domains as recommended by the WHOQOL study group [59]. Thereafter, we computed values for the domains corresponding with the $14-15 ; 16-17 ; 18$ - 19; and 20-23 - year age groups. To determine the prevalence of those at risk status for impaired QOL, we dichotomized the domain scores at $<1 S D$ of the population mean [30]. Based on our results, the cut - off scores were $<53.7$ (physical health), $<44.1$ (psychological health), $<50.8$ (social relations), $<52.4$ (environment domain), and $<47.2$ (general facet on health \& OQOL).. Using the national census data, the prevalence rate of at risk status for poor QOL in each domain was adjusted by age and sex to the Kuwaiti population, in order to estimate the number of people with poor QOL at the ages we studied in the national population.

\section{Psychological distress and self-esteem}

Designated items for anxiety, depression and anger were selected from the Trauma Symptom Checklist for
Children, by Briere [60]. This was because our methodology could not be used to diagnose anxiety and depression, and we wished to reduce respondent burden and ensure reliability of responses [22,23]. The following items were chosen because they were most reflective of the corresponding American DSM-IV ${ }^{\mathrm{TR}}$ symptoms: (a) Anxiety: Items 2, 15, 32, and 41; (b) Depression: Items 7, 9, 28, 42, and 52 . Item 52 was modified because of the sanctions by the Islamic culture on suicide, to read: "Wishing I were dead"; (c) Anger: Items 19, 16, 21 and 22.

Test - retest reliability (intra class correlation coefficient) for 47 subjects with full data for the retest exercise at the preliminary stage of the study was $0.90(95 \%$ C. I. $=0.85-0.94)$. For the entire population of participants $(N=4467)$, internal consistency was 0.87 . The item scores were summed up to generate total scores for anxiety and depression.

The 10-item Rosenberg's scale [61] was used to assess self-esteem.

\section{Socio-environmental factors}

$>$ As there are no available formal instruments to assess the socio-environmental factors of interest to this study, and in order to reduce respondent burden [23], we assessed this domain with a few number of items that we articulated specifically for this study, based on our clinical experience of children in this culture, thus:

(i) one item on perceived quality of emotional relationship between the parents (response options: poor, fair, good, excellent) [6,9]; (ii) difficulty in psychosocial functioning. This was assessed by three items concerning difficulties being encountered as a result of various activities, viz: difficulty with studies (yes/no); difficulty relating with friends (yes/no); experiencing any other difficulties (yes/no); (iii) one item on perceived need for medical or psychological help (response options: no problem, need help only from friends, need medical/psychological help but not receiving it, need medical/ psychological help and receiving it).

\section{Data analysis}

Data were analyzed by SPSS version 15 for Windows (SPSS Inc., Chicago, Illinois). We examined the frequency distribution of the scores. Since the QOL domains scores were not normally distributed, we examined the association of socio-demographic factors and self - rated current illness with QOL domain scores using non - parametric tests of significance (Kruskal - Walis' chi-square and Mann-Whitney U test); and used Spearman's correlation to assess the relationship between anxiety/depression scores and QOL domain scores. The possible contribution of covariates (e.g., anxiety, depression, self-esteem and 
psychosocial difficulties) to sex and age differences in QOL scores was assessed by analysis of covariance (ANCOVA). We used multiple regression analyses to assess the associations of QOL in the multivariate context, with scores on the general facet and each of the domains as dependent variables. Based on the literature [31], the independent variables were entered in five different blocks, thus: Step 1: background sociodemographics; step 2: the quality of parental emotional relationship, difficulty with studies and difficulty with social relationships; step 3: self-esteem score; step 4: anxiety score; and step 5: depression score. Multi-collinearity was assessed by the values of "tolerance" (cutoff score $</=0.2$ ) and variance inflation factor (VIF cut-off score $>4.0$ ) [62]. The level of statistical significance was set at $p<0.05$. Missing data were handled by excluding cases analysis by analysis.

\section{Results}

Satisfaction with circumstances of life: (Table 1)

Using the criteria previously defined, we found that the pattern of satisfaction was in line with their material circumstance. Hence, for a mostly healthy population in a materially affluent and conservative society, at least three - quarters of subjects felt satisfied with availability of money for their needs $(3382 / 4407$ or $76.7 \%$ ), and felt no need for treatment (3286/4409 or $74.5 \%$ ); while over two-thirds were satisfied with access to health services $(2969 / 4421$ or $67.2 \%)$. Furthermore, in line with the obvious restrictions on leisure opportunities in this society, less than one - half were satisfied with available opportunity for leisure activities (2014/4420 or $45.6 \%)$; and probably as indicative of their concern with their studies, they were also generally not satisfied with their ability to concentrate $(1805 / 4431$ or $40.7 \%)$.
Pattern of QOL domain scores (Table 2 and Table 3)

Table 3 shows that the unadjusted prevalence of "at risk status for impaired QOL" $[9,30]$ for various domains was $12.9 \%-18.8 \%$, while the age and sex adjusted rates were $15.9 \%-21.1 \%$.

Using Cummins' recommendation of 70\% - 80\% [52], we found that, as a group, the students barely achieved the psychosocial well-being threshold score of $70 \%$ for all domains, except psychological health where they scored $61.9 \%$ (see Table 2, bottom rows). In particular, this pattern was characteristic of the boys aged $14-15$ and $16-17$. In the case of the girls, only the youngest achieved the threshold score of $70 \%$ for physical health, social relations and environment domains and general facet.

\section{Age and gender differences in QOL}

In all domains and for both sexes, quality of life decreased with age, such that those aged 14-15 and 1617 years had significantly higher scores than those aged $18-19$ and $20-23$ years $\left(K W \chi^{2}=13.9-93.4, \mathrm{df}=3, p<\right.$ 0.001) (Table 2). Accordingly, in all domains, correlation of age with QOL was negative, though of small magnitude (rho $=-0.07-0.16)$, but significant $(p<0.001)$.

In all domains, males had significantly higher QOL than females $(M-W U=1859917-2262080, \mathrm{Z}=5.2$ 11.6, $p<0.0001)$, and there was a significantly higher prevalence of at risk status for impaired QOL among the girls $\left(\chi^{2}\right.$ ranged from 10.6 to $47.8, d f=1, p<0.001$ for all domains, except for social relations $-\chi^{2}=4.5$ where the level of significance was $p<0.035$ ) (Table 3).

\section{Other factors associated with QOL}

There was consistent evidence of significantly poorer QOL with social disadvantage. Thus, in all domains, QOL was poorer for subjects whose parents were either

Table 1 Frequency distribution of WHOQOL-Bref items*

\begin{tabular}{|c|c|c|c|c|c|c|c|}
\hline \multirow{2}{*}{$\begin{array}{l}\text { Highly satisfied**: } \\
\text { Item }\end{array}$} & \multirow[b]{2}{*}{$\%$} & \multicolumn{2}{|c|}{ Moderate satisfaction**: } & \multicolumn{2}{|l|}{ Bare satisfaction**: } & \multicolumn{2}{|l|}{ Dissatisfied ${ }^{* *}$ : } \\
\hline & & Item & $\%$ & Item & $\%$ & Item\% & $\%$ \\
\hline Ability to get around & 85.3 & Self-satisfaction & 68.2 & Overall QOL & 63.9 & Ability to concentrate & 40.7 \\
\hline Condition of place of living & 74.9 & Transport & 73.7 & No physical pain & 60.8 & Leisure opportunity & 45.6 \\
\hline Need for treatment & 74.5 & Health & 65.8 & Enjoyment of life & 50.6 & No negative feeling & 18.4 \\
\hline \multirow[t]{7}{*}{ Money } & 76.7 & Safety & 70.2 & Physical environment & 54.8 & & \\
\hline & & Personal relations & 72.2 & Bodily appearance & 63.5 & & \\
\hline & & Energy & 72.5 & Available information for health & 54.6 & & \\
\hline & & Friends' support & 67.8 & Activities of daily living & 57.5 & & \\
\hline & & Access health services & 67.2 & Sexual feeling(63.6); & 63.6 & & \\
\hline & & & & Life meaningful(57.4); & 57.4 & & \\
\hline & & & & Sleep & 55.4 & & \\
\hline
\end{tabular}

\footnotetext{
* Because of missing data, N was variously: 4407 - 4458

** Operational definition: We quantified satisfaction with each item as at least $50 \%$ of respondents in the sample positively appreciating the item (i.e., proportion of subjects in the group who rated satisfaction for the item as "satisfied" or "very satisfied"); dissatisfaction ( $<50 \%$ were satisfied/very satisfied with item); bare satisfaction (50 - 65\%); moderate satisfaction (66 - 74\%); and highly satisfied $(\geq 75 \%)[51,56]$
} 
Table 2 Normative values of subjective quality of life domain scores by age groups*

\begin{tabular}{|c|c|c|c|c|c|}
\hline & $\begin{array}{l}\text { Physical } \\
\text { health }\end{array}$ & $\begin{array}{l}\text { Psychological } \\
\text { health }\end{array}$ & $\begin{array}{l}\text { Social relations } \\
\text { Domain }\end{array}$ & $\begin{array}{l}\text { Environment } \\
\text { domain }\end{array}$ & $\begin{array}{l}\text { General facet on health \& } \\
\text { OQOL }\end{array}$ \\
\hline Age groups*yrs: Males** & $\begin{array}{l}\text { Mean(SD) } \\
{[95 \% \text { C.I] }}\end{array}$ & $\begin{array}{l}\text { Mean(SD) } \\
{[95 \% \text { C.I] }}\end{array}$ & $\begin{array}{l}\text { Mean(SD) } \\
{[95 \% \text { C.I] }}\end{array}$ & $\begin{array}{l}\text { Mean(SD) } \\
{[95 \% \text { C.I] }}\end{array}$ & $\begin{array}{l}\text { Mean(SD) } \\
{[95 \% \text { C.I] }}\end{array}$ \\
\hline 14-15: $N=230$ & $\begin{array}{l}75.3(16.3) \\
{[73.1-77.4]}\end{array}$ & $\begin{array}{l}66.8(17.5) \\
{[64.5-69.2]}\end{array}$ & $\begin{array}{l}75.8(21) \\
{[73.0-78.5]}\end{array}$ & $\begin{array}{l}74.9(17.5) \\
{[72.6-77.3]}\end{array}$ & $\begin{array}{l}73.8(24) \\
{[70.7-76.9]}\end{array}$ \\
\hline $16-17: N=1338$ & $\begin{array}{l}72.5(15.6) \\
{[71.6-73.3]}\end{array}$ & $\begin{array}{l}65.4(17.2) \\
{[64.2-66.3]}\end{array}$ & $\begin{array}{l}74.4(22) \\
{[73.3-75.6]}\end{array}$ & $\begin{array}{l}73.5(17.1) \\
{[72.0-74.5]}\end{array}$ & $\begin{array}{l}71.8(22) \\
{[71.6-73.9]}\end{array}$ \\
\hline 18-19: $N=527$ & $\begin{array}{l}69.0(15.5) \\
{[67.7-70.4]}\end{array}$ & $\begin{array}{l}64.4(17.1) \\
{[62.9-65.9]}\end{array}$ & $\begin{array}{l}73.6(22) \\
{[71.7-75.4]}\end{array}$ & $\begin{array}{l}70.5(17.6) \\
{[68.9-72.1]}\end{array}$ & $\begin{array}{l}69.9(23) \\
{[68.0-71.9]}\end{array}$ \\
\hline 20-23: $N=62$ & $\begin{array}{l}67.3(13.3) \\
{[63.8-70.8]}\end{array}$ & $\begin{array}{l}59.9(16.8) \\
{[55.6-64.3]}\end{array}$ & $\begin{array}{l}70.4(20) \\
{[65.2-75.6]}\end{array}$ & $\begin{array}{l}67.0(17.9) \\
{[62.3-71.7]}\end{array}$ & $\begin{array}{l}65.5(22) \\
{[60.0-71.0]}\end{array}$ \\
\hline Total: $N=2157$ & $\begin{array}{l}71.8(15.7) \\
{[71.1-72.5]}\end{array}$ & $\begin{array}{l}65.1(17.2) \\
{[64.4-65.9]}\end{array}$ & $\begin{array}{l}74.2(21) \\
{[73.3-75.2]}\end{array}$ & $\begin{array}{l}72.8(17.4) \\
{[71.9-73.5]}\end{array}$ & $\begin{array}{l}72.0(23) \\
{[71.0-72.9]}\end{array}$ \\
\hline Adjusted scores (SE): All males*** & $\begin{array}{l}71.1(0.34) \\
{[70.4-71.7]}\end{array}$ & $\begin{array}{l}63.7(0.33) \\
{[63.1-64.4]}\end{array}$ & $\begin{array}{l}73.5(0.46) \\
{[72.6-74.4]}\end{array}$ & $\begin{array}{l}71.7(0.37) \\
{[70.9-72.4]}\end{array}$ & $\begin{array}{l}70.5(0.45) \\
{[69.6-71.4]}\end{array}$ \\
\hline Females** & $\begin{array}{l}\text { Physical } \\
\text { health }\end{array}$ & $\begin{array}{l}\text { Psychological } \\
\text { health }\end{array}$ & Social relations & $\begin{array}{l}\text { Environment } \\
\text { domain }\end{array}$ & $\begin{array}{l}\text { General facet on health \& } \\
\text { OQOL }\end{array}$ \\
\hline 14-15: $N=234$ & $\begin{array}{l}73.2(15.1) \\
{[71.2-75.2]}\end{array}$ & $\begin{array}{l}61.1(18.0) \\
{[58.8-63.5]}\end{array}$ & $\begin{array}{l}74.9(19) \\
{[72.3-77.4]}\end{array}$ & $\begin{array}{l}71.7(18.0) \\
{[69.3-74.1]}\end{array}$ & $\begin{array}{l}72.7(22) \\
{[69.8-75.5]}\end{array}$ \\
\hline 16-17: $N=1432$ & $\begin{array}{l}69.3(16.4) \\
{[68.4-70.1]}\end{array}$ & $\begin{array}{l}59.8(17.7) \\
{[58.9-60.7]}\end{array}$ & $\begin{array}{l}71.7(21) \\
{[70.6-72.9]}\end{array}$ & $\begin{array}{l}70.5(18.7) \\
{[69.5-71.5]}\end{array}$ & $\begin{array}{l}69.3(23) \\
{[68.1-70.5]}\end{array}$ \\
\hline 18-19: $N=554$ & $\begin{array}{l}64.6(16.8) \\
{[63.2-66.0]}\end{array}$ & $\begin{array}{l}56.7(17.6) \\
{[55.3-58.2]}\end{array}$ & $\begin{array}{l}69.3(22) \\
{[67.4-71.2]}\end{array}$ & $\begin{array}{l}64.9(19.6) \\
{[63.3-66.7]}\end{array}$ & $\begin{array}{l}65.7(24) \\
{[63.8-67.7]}\end{array}$ \\
\hline 20-23: $N=56$ & $\begin{array}{l}61.4(17.5) \\
{[56.4-66.3]}\end{array}$ & $\begin{array}{l}51.2(20.4) \\
{[45.7-56.7]}\end{array}$ & $\begin{array}{l}67.6(24) \\
{[61.1-74.2]}\end{array}$ & $\begin{array}{l}60.9(20.3) \\
{[55.3-66.5]}\end{array}$ & $\begin{array}{l}57.1(26) \\
{[50.2-64.1]}\end{array}$ \\
\hline Total: $N=2276$ & $\begin{array}{l}68.4(16.6) \\
{[67.7-69.0]}\end{array}$ & $\begin{array}{l}58.9(17.0) \\
{[58.2-59.7]}\end{array}$ & $\begin{array}{l}71.3(21) \\
{[70.5-72.2]}\end{array}$ & $\begin{array}{l}69.0(19.1) \\
{[68.2-69.8]}\end{array}$ & $\begin{array}{l}68.5(23) \\
{[67.5-69.4]}\end{array}$ \\
\hline $\begin{array}{l}\text { Adjusted scores (SE): All } \\
\text { females*** }\end{array}$ & $\begin{array}{l}69.7(0.33) \\
{[69.1-70.4]}\end{array}$ & $\begin{array}{l}60.6(0.33) \\
{[59.9-61.3]}\end{array}$ & $\begin{array}{l}72.6(0.46) \\
{[71.7-73.5]}\end{array}$ & $\begin{array}{l}70.7(0.36) \\
{[69.9-71.4]}\end{array}$ & $\begin{array}{l}70.5(0.32) \\
{[69.7-71.4]}\end{array}$ \\
\hline $\begin{array}{l}\text { All participants: } \\
N=4276\end{array}$ & $\begin{array}{l}70.0(16.3) \\
{[69.5-70.5]}\end{array}$ & $\begin{array}{l}61.9(17.8) \\
{[61.4-62.5]}\end{array}$ & $\begin{array}{l}72.8(21) \\
{[72.1-73.4]}\end{array}$ & $\begin{array}{l}70.8(18.4) \\
{[70.3-71.4]}\end{array}$ & $\begin{array}{l}70.2(23) \\
{[69.5-70.9]}\end{array}$ \\
\hline $\begin{array}{l}\text { Adjusted scores (SE): All } \\
\text { participants*** }\end{array}$ & $\begin{array}{l}70.4(0.24) \\
{[69.9-70.9]}\end{array}$ & $\begin{array}{l}62.2(0.23) \\
{[61.7-62.6]}\end{array}$ & $\begin{array}{l}73.1(0.32) \\
{[72.4-73.7]}\end{array}$ & $\begin{array}{l}71.2(0.26) \\
{[70.7-71.7]}\end{array}$ & $\begin{array}{l}70.5(0.32) \\
{[69.9-71.1]}\end{array}$ \\
\hline
\end{tabular}

* Using the 0-100\% scoring method: Mean (SD) [95\% Confidence Intervals]

* In all domains and for both sexes, quality of life decreased with age, such that those aged 14-15 and 16-17 had significantly higher scores than those aged 1819 and 20-23: $\mathrm{KW} \chi^{2}=13.9-93.4, \mathrm{df}=3, P<0.001$..

** In all domains, males had significantly higher QOL than females: Mann-Whitney $U=1859917-2262080, Z=5.2-11.6, P<0.0001$.

*** Adjusted for age, father's occupation, depression and anxiety scores.

divorced or fathers had either lower occupational status or were unemployed (M-WU: $401233-475588, Z=3.3$ - 6.7, $p<0.001$ ). For mother's occupational status, the trend reached significance only in the physical health domain $\left(K W \chi^{2}=7.5, d f=2, p<0.02\right)$.

In all domains, QOL was significantly correlated with self-esteem $(r h o>0.40)$, and negatively correlated with depression (rho > - 0.40). Also, domains of QOL were negatively correlated with anxiety (rho $>-0.40, p<$ 0.0001 ), except social relations (rho $=-0.29, p>0.05$ ). In all domains, QOL decreased with poorer perception of the quality of emotional relationship between parents $\left(K W \chi^{2}=315-767.9, d f=3, p<0.0001\right)$. In all domains, those who expressed difficulty in social relationships, as well as with their studies, and general situations, and admitted having general health or psychological problems, had significantly poorer QOL
$(M-W U=968408-1128935 ; Z=15.1-21.0, p<$ 0.0001).

\section{Covariance analysis}

It was necessary to do analysis of covariance in order to understand the impact of anxiety, depression, selfesteem and difficulty with studies and social relations on the noted age and gender differences in QOL. This is because these variables had gender and age differences, while being significantly associated with QOL. For example, the boys had significantly higher self-esteem scores than the girls (boys:30.7, SD 4.5, vs. girls: 30.1, SD 4.7) $(t=4.0, d f=4195, p<0.001)$, while the girls had significantly higher anxiety (girls:13.9, SD 3.9, vs. boys: 12.9, SD 3.8) and depression scores (11.5, SD 3.7, vs. 10.4, SD 3.4) than the boys $(t=9.7-13.9, d f=4231$, $p<0.001)$. Similarly, difficulty with studies $\left(\chi^{2}=49.7, d f\right.$ 
Table 3 Prevalence of normal/poor (at risk status for impaired) QOL by gender*

\begin{tabular}{|c|c|c|c|c|c|c|c|c|c|c|}
\hline \multirow[b]{2}{*}{ QOL Domains } & \multicolumn{3}{|c|}{ All study participants } & \multicolumn{3}{|c|}{ Boys' QOL } & \multicolumn{3}{|c|}{ Girls' QOL } & \multirow{2}{*}{$\begin{array}{l}\text { Statistics } \\
P \text { level } \\
\text { Boys vs. } \\
\text { Girls }\end{array}$} \\
\hline & $\begin{array}{l}\text { Normal } \\
\%\end{array}$ & $\begin{array}{l}\text { Poor } \\
\%\end{array}$ & $\begin{array}{l}\text { Age adjusted } \\
* *[95 \% \text { C.I. }]\end{array}$ & $\begin{array}{l}\text { Normal } \\
\%\end{array}$ & $\begin{array}{l}\text { Poor } \\
\%\end{array}$ & $\begin{array}{l}\text { Age adjusted } \\
* *[95 \% \text { C.I. }]\end{array}$ & $\begin{array}{l}\text { Normal } \\
\%\end{array}$ & $\begin{array}{l}\text { Poor } \\
\%\end{array}$ & $\begin{array}{l}\text { Age adjusted }{ }^{* *} \\
{[95 \% \text { C.I.] }}\end{array}$ & \\
\hline $\begin{array}{l}\text { Physical health } \\
N=4276 ; \\
\text { Boys 2073 } \\
\text { Girls } 2203\end{array}$ & 82.1 & 17.9 & $\begin{array}{l}21.1 \\
{[20.9-21.3]}\end{array}$ & 85.4 & 14.6 & $\begin{array}{l}15.9 \\
{[15.7-16.1]}\end{array}$ & 79.0 & 21.0 & $\begin{array}{l}27.1 \\
{[26.8-27.4]}\end{array}$ & 0.0001 \\
\hline $\begin{array}{l}\text { Psycholo-gical } \\
N=4322 \\
\text { Boys } 2091\end{array}$ & 84.2 & 15.8 & $\begin{array}{l}19.2 \\
{[19.0-19.4}\end{array}$ & 88.1 & 11.9 & $\begin{array}{l}12.9 \\
{[12.7-13.1]}\end{array}$ & 80.5 & 19.5 & $\begin{array}{l}25.5 \\
{[25.2-25.8]}\end{array}$ & 0.0001 \\
\hline $\begin{array}{l}\text { Social relations } \\
N=4273 \\
\text { Boys } 2091\end{array}$ & 81.2 & 18.8 & $\begin{array}{l}20.1 \\
{[19.9-20.3]}\end{array}$ & 82.5 & 17.5 & $\begin{array}{l}17.8 \\
{[17.6-18.0]}\end{array}$ & 80.0 & 20.0 & $\begin{array}{l}23.7 \\
{[23.4-23.9]}\end{array}$ & 0.035 \\
\hline $\begin{array}{l}\text { Environ-ment } \\
N=4223 \\
\text { Boys } 2031\end{array}$ & 84.3 & 15.7 & $\begin{array}{l}18.7 \\
{[18.5-18.9]}\end{array}$ & 87.7 & 12.3 & $\begin{array}{l}15.7 \\
{[15.5-15.9]}\end{array}$ & 81.2 & 18.8 & $\begin{array}{l}21.5 \\
{[21.3-21.8]}\end{array}$ & 0.0001 \\
\hline $\begin{array}{l}\text { General facet } \\
N=4456 \\
\text { Boys } 2164\end{array}$ & 87.1 & 12.9 & $\begin{array}{l}15.9 \\
{[15.8-16.1]}\end{array}$ & 88.8 & 11.2 & $\begin{array}{l}13.4 \\
{[13.2-13.6]}\end{array}$ & 85.6 & 14.4 & $\begin{array}{l}18.2 \\
{[17.9-18.4]}\end{array}$ & 0.0001 \\
\hline
\end{tabular}

* As defined by scores < 1SD population mean (see last row of Table 2 by gender) for each domain

** Prevalence rates were adjusted to the 2007 Kuwaiti population to estimate the number of children with at risk status for poor QOL at the ages that were studied in the general population

$=3, p<0.0001)$ and social relationships $\left(\chi^{2}=5.9, d f=\right.$ $1, p<0.02)$ increased significantly with age.

In ANCOVA, we found that, after controlling for difficulty with studies and social relations, the previously noted age group differences in QOL narrowed considerably, such that the following pattern emerged:

(i) For psychological health and social relations, the differences were no longer significant $(p>0.05)$.

(ii) Physical health: those aged 14-15 had significantly higher scores $(p<0.001)$; but the scores for those aged $16-17$ years $(70.5 \%)$ were no longer significantly different from the scores for those aged 18-19 (67.4\%) and $20-23$ years $(67.4 \%)(p>0.05)$. The same pattern was noted for the environment domain and general facet.

Similarly, after adjusting for the scores on anxiety and depression, gender differences in QOL domain scores narrowed considerably in most domains (from $p$ $<0.0001$ for the unadjusted scores) to produce the following pattern for boys and girls, respectively: (i) physical health: $70.9 \%$ vs. $69.4 \%(p<0.002)$; (ii) psychological health: $63.5 \%$ vs. $60.6 \%(p<0.0001)$; (iii) for environment: $71.7 \%$ vs. $70.5 \%(p<0.02)$; and (iv) the differences were no longer significant for social relations $(73.3 \%$ vs. $72.8 \%)$ and the general facet $(70.1 \%$ vs. $70.5 \%)(p>0.05)$.

However, the significant gender differences in quality of life seemed not to have been affected by difficulty with studies and social relationships $(p<0.001)$.

In other words, the mediators for age differences in QOL were difficulty with studies and social relations, while the mediators for gender differences were anxiety and depression.
Regression analyses: associations of QOL in multivariate contexts (Table 4)

\section{Summary of predictors of QOL from the perspective of the} conceptual framework

Using the model of Jirojanakul et al [13], the results of the regression analyses showed that variables from the personal factors (age and sex), parental factors (parental marital status and father's occupation), general health factors (self-esteem, anxiety and depression) and socioenvironmental factors (quality of parental emotional relationship, difficulty with studies and social relationship) were variously important in predicting domains of QOL (Table 4). However, the variables that accounted for at least $5 \%$ of variance in any domain were: quality of parental emotional relationship (6.1\% - 17.7\%, except physical health, 3.7\%), difficulty with studies $(7.3 \%$ $14.7 \%$, except social relations, $0.6 \%)$, and self-esteem $(7.9 \%-18.6 \%)$. Although anxiety and depression contributed les than $4 \%$ of variance, they were consistently highly significant predictors $(p<0.001)$ of QOL, and played greater roles than the personal and parental background factors. In particular, the contribution of gender to various domains of QOL seemed to disappear when the psychological factors entered the equation. In other words, the contribution of personal and parental background factors to QOL seemed to be important because of the impact they had on the child's psychological status.

\section{Discussion}

We assessed the subjective QOL of a nation-wide sample of Kuwaiti high school students using the WHOQOL- 
Table 4 Factors associated with domains of QOL in multivariate context*

\begin{tabular}{|c|c|c|c|c|}
\hline Dependent variable & Independent variables or Predictors & $\%$ Variance or $R$ square ${ }^{* *}$ & Standardized beta & $P$ : level of significance ${ }^{* * *}$ \\
\hline \multirow[t]{10}{*}{ General facet health/QOL } & Age & 1.4 & -0.06 & 0.001 \\
\hline & Parental marital status & 1.2 & 0.04 & 0.02 \\
\hline & Gender & 0.5 & 0.008 & 0.58 \\
\hline & Father's occupation & 0.4 & 0.03 & 0.05 \\
\hline & Parental emotional relationship & 15.8 & 0.25 & 0.001 \\
\hline & Difficulty with studies & 7.3 & -0.11 & 0.001 \\
\hline & Difficulty in social relationships & 0.8 & 0.006 & 0.72 \\
\hline & Self-esteem score & 7.9 & 0.20 & 0.001 \\
\hline & Anxiety score & 3.5 & -0.12 & 0.001 \\
\hline & Depression score & 1.5 & -0.19 & 0.001 \\
\hline \multirow[t]{10}{*}{ Physical health } & Age & 3.0 & -0.12 & 0.001 \\
\hline & Gender & 0.8 & 0.04 & 0.02 \\
\hline & Father's occupation & 0.5 & 0.03 & 0.11 \\
\hline & Parental marital status & 0.4 & 0.02 & 0.19 \\
\hline & Difficulty with studies & 12.3 & -0.15 & 0.001 \\
\hline & Parental emotional relationship & 3.7 & 0.11 & 0.001 \\
\hline & Difficulty in social relationships & 0.8 & -0.02 & 0.39 \\
\hline & Self-esteem score & 8.8 & 0.26 & 0.001 \\
\hline & Anxiety score & 2.5 & -0.15 & 0.001 \\
\hline & Depression score & 0.2 & -0.07 & 0.007 \\
\hline \multirow[t]{7}{*}{ Psychological health } & Gender & 2.8 & 0.09 & 0.001 \\
\hline & Age & 1.0 & -0.05 & 0.001 \\
\hline & Difficulty with studies & 14.7 & -0.09 & 0.001 \\
\hline & Parental emotional relationship & 8.6 & 0.17 & 0.001 \\
\hline & Self-esteem & 18.6 & 0.36 & 0.001 \\
\hline & Anxiety & 2.7 & -0.06 & 0.001 \\
\hline & Depression & 2.6 & -0.26 & 0.001 \\
\hline \multirow[t]{7}{*}{ Social relations } & Age & 0.6 & -0.04 & 0.01 \\
\hline & Parental emotional relationship & 6.1 & 0.12 & 0.001 \\
\hline & Difficulty in social relations & 3.8 & -0.05 & 0.007 \\
\hline & Difficulty with studies & 0.6 & 0.003 & 0.88 \\
\hline & Self-esteem & 9.0 & 0.25 & 0.001 \\
\hline & Anxiety & 0.5 & 0.03 & 0.19 \\
\hline & Depression & 2.1 & -0.23 & 0.001 \\
\hline \multirow[t]{6}{*}{ Environment } & Age & 1.6 & -0.07 & 0.001 \\
\hline & Parental emotional relationship & 17.7 & 0.28 & 0.001 \\
\hline & Difficulty with studies & 7.4 & -0.10 & 0.001 \\
\hline & Self - esteem & 8.7 & 0.23 & 0.001 \\
\hline & Anxiety & 1.9 & -0.05 & 0.01 \\
\hline & Depression & 1.9 & -0.22 & 0.001 \\
\hline
\end{tabular}

* Final stepwise regression model

** Total $\%$ of variance explained: general facet $=40.3$; physical health $=33.2 ;$ psychological health $=54.4 \%$; social relations $=24.0 \%$; environment $=43.6 \%$

*** Values of "tolerance" (cut-off score $</=0.2$ ) and variance inflation factor (VIF - cut-off score $>4.0$ ) indicate no significant multi-collinearity.

Bref, and examined the association of domains of QOL with several factors. This is the first of such a report from the Arab world for this age group. In line with the impression that QOL is sensitive to psychosocial distress [31], we found that the pattern of satisfaction was in consonance with the subjects' material and socio-cultural circumstances; and our findings indicated that poorer QOL was significantly associated with female gender, older age, indices of social disadvantage, psychic distress and social/ academic pressures. What we have added to the literature are: the estimation of prevalence of at risk status for impaired QOL, thus making our findings clinically relevant as a population health outcome $[4,7,9]$; the presentation of normative values for this population (thus 
establishing benchmarks for comparison with clinical groups in the region); and the emphasis on the importance of child's perception of the quality of parental emotional relationship.

\section{Pattern of QOL domain scores}

Although the average QOL scores of most domains for our subjects marginally met the $70 \%$ cut-off recommended by Cummins, and which is supported by data from several countries, the pattern of scores was similar to the international data because in all the available reports $[9,11,12,15,16,30,38]$, the score for the psychological health domain was the least, in comparison with all other domains of QOL. It has been suggested that the low score on psychological health indicates that the students need access to programs and services that address their mental health needs [8]. The particularly low psychological health score for Kuwaiti students (61.9\%) makes this recommendation highly relevant, especially for boys aged 20-23 years, and girls aged 1623, who had average scores less than $60 \%$ (Table 2). This low score in the psychological health domain for our subjects is reflective of the reported relatively high rate of anxiety/depression morbidity among the youth in Kuwait (compared with the international data) [63-66].

Furthermore, judging by the average scores, it appears that the Kuwaiti students had lower QOL scores than their counterparts from other parts of the world. With regard to our finding of prevalence of at risk status for impaired QOL (12.9\% - 18.8\%), there are only data from Austria (15\%) [9] and the USA (14-17\%) [30] to compare with. Hence, there is need for more reports that present pediatric QOL data from the perspective of clinical relevance [51]. This perspective is important because it has been suggested that low QOL scores reflect children's perception of impaired psychological and physical health, with potential implications for the success of children in their living environments [8]. Hence, identifying the child with low QOL allows for early detection of hidden morbidity and health care needs [21]. In conclusion, our findings did not support our hypothesis that the average QOL domain scores for students in Kuwait would be high, in comparison with the international data. This dissonance between material living circumstance and QOL has been well noted in the literature $[67,68]$.

\section{Factors associated with QOL}

While our findings about gender and age differentials in QOL are similar to the international trend, the difference is that in Kuwait, the gender differences in QOL were more pronounced, affecting all domains at highly significant levels. The relatively low score in the psychological health domain $(<57 \%)$ for girls aged $18-23$ exemplifies the situation for the older girls as has been described by Arab scholars, consequent on the sociocultural situation $[17,69,70]$. What we have added to the literature is the finding that the gender differences in QOL scores were mediated by anxiety and depression. The implication is that the condition of the girls with problems can be alleviated by school health programs that focus on promotion of mental health. Similarly, our finding that the age differences in QOL were mediated by difficulties that the older students were experiencing with their greater burden of school work and demands for social relationships [19] implies that school - based programs that include making the school atmosphere more study - friendly have the potential to improve the QOL of students. These findings complement the results of our regression analyses. The finding about the predictive power of the child's perception of parental emotional relationship has been reported for psychopathology [71] and is supported by attachment theory [72]. The clinical implication is that those engaged in family work should emphasize the benefit of parental harmony on the well-being of the child [73].

Our finding on the role of the parental socio-economic situation supports the suggestion that children whose parents are socially disadvantaged need focused attention in school if their QOL is low [74].

\section{Limitations and strengths}

The major limitation of the study is that it was crosssectional; hence the results support an association, not causality. Moreover, the variables not measured, such as parental age, and monogamy/polygamy family setting could have contributed to the impact of quality of emotional relationship between the parents. The strengths of our study are that we studied a nation-wide sample using an internationally validated instrument, based on a conceptual framework, and we analyzed our data in such a way as to make QOL data clinically relevant as a population health measure. We needed to modify the item on sexual activity (because it is not appropriate in the culture) and it is arguable whether the replacement with sexual feeling is adequate. However, the adequate reliability indices of the instrument in our sample shows that the modifications we made have not diminished the noted satisfactory psychometric characteristics of the Arabic translation of the WHOQOL-Bref in this setting [36].

\section{Conclusion}

The findings support the view that QOL is sensitive to psychosocial living situation. Hence, poor quality of life seemed to reflect a circumstance of social disadvantage and poor psychological well-being in which girls fared worse than boys. The findings indicate that programs 
that address parental harmony, as well school programs that promote student-friendly atmospheres (such as "School-Wide Positive Behavioral Interventions and Supports") [75] could help to improve the subjective QOL of the students.

\section{Acknowledgements}

The study was sponsored by a grant from the Kuwait Society for the Advancement of Arab Children (KSAAC). The Ministry of Education authorized and facilitated the study. The following played invaluable roles in data collection: Zaina Al-Zabin, Nahed Kamel, Abdel W. Awadalla, and Sumai (and Ministry of Education Headquarters counseling unit staff). Joy Wilson for data entry. We are most grateful to the school psychologists for administering the questionnaires. We thank the school principals and the students for their cooperation.

\section{Author details}

${ }^{1}$ Department of Psychiatry, Faculty of Medicine, Kuwait University, Kuwait ${ }^{2}$ Department of Psychiatry, Psychological Medicine Hospital, Gamal Abdul Naser Road, P.O. Box 4081, Safat, Kuwait.

\section{Authors' contributions}

GAA and JUO designed the study, analyzed the data and prepared the manuscript. All the authors read the manuscript and approved it.

\section{Competing interests}

The authors declare that they have no competing interests.

Received: 25 November 2010 Accepted: 25 April 2011

Published: 25 April 2011

\section{References}

1. Pal DK: Quality of life assessment in children: a review of conceptual and methodological issues in multidimensional health status measures. $J$ Epidemiol Community Health 1996, 50:391-396.

2. Center for Human Rights, United Nations: Convention on the Rights of the Child Geneva: United Nations; 1989.

3. Vingilis ER, Wade TJ, Seeley JS: Predictors of adolescent self-rated health. Analysis of the National Population Health Survey. Can J Public Health 2002, 93:193-197.

4. Varni JW, Burwinkle TM, Seid M: The PedsQL ${ }^{\mathrm{TM}} 4.0$ as a school population health measure: feasibility, reliability and validity. Qual Life Res 2006 15:203-215.

5. Simon AE, Chan KS, Forrest CB: Assessment of children's health-related quality of life in the United States with a multidimensional index. Pediatrics 2008, 121:e118-e126.

6. Kim HK, Viner-Brown SI, Garcia J: Children's mental health and family functioning in Rhode Island. Pediatrics 2007, 119:S22-S28.

7. Pantzer K, Rajmil L, Tebe C, Codina F, Serra-Sutton V, Ferrer M, Ravens Sieberer U, Simeoni M-C, Alonso J: Health-related quality of life in immigrants and native school aged adolescents in Spain. J Epidemiol Community Health 2006, 60:694-698.

8. Mansour ME, Kotagal U, Rose B, Ho M, Brewer D, Roy-Chaudhury A, Hornung RW, Wade TJ, DeWitt TG: Health-related quality of life in urban elementary school children. Pediatrics 2003, 111:1372-1381.

9. Felder-Puig R, Baumgartner M, Topf R, Gadner H, Formann AK: Healthrelated quality of life in Austrian elementary school children. Med Care 2008, 46:432-439.

10. Gkoltsiou K, Dimitrakaki C, Tzavara C, Papaevangelou V, Varni JW, Tountas Y: Measuring health-related quality of life in Greek children: psychometric properties of the Greek version of the Pediatric Quality of Life Inventory(TM) 4.0 Generic Core Scales. Qual Life Res 2008, 17:299-305.

11. Collier J, MacKinlay D, Phillips D: Norm values for the Generic Children's Quality of Life measure from a large school-based sample. Qual Life Res 2000, 9:617-623.

12. Kook SH, Varni JW: Validation of the Korean version of the pediatric quality of life inventory 4.0 (PedsQL) generic core scales in school children and adolescents using the Rasch model. Health Qual Life Outcomes 2008, 6:41.

13. Jirojanakul P, Skevington SM, Hudson J: Predicting young children's quality of life. Soc Sci Med 2003, 57:1277-1288

14. Chen X, Origasa H, Ichida F, Kamibeppu K, Varni JW: Reliability and validity of the Pediatric Quality of Life Inventory (PedsQL) Short Form 15 Generic Core Scales in Japan. Qual Life Res 2007, 16:1239-1249.

15. Klatchoian DA, Len CA, Terreri MT, Silva M, Itamoto C, Ciconelli RM, Varni JW, Hilário MO: Quality of life of children and adolescents from São Paulo: reliability and validity of the Brazilian version of the Pediatric Quality of Life Inventory version 4.0 Generic Core Scales. J Pediatr (Rio J) 2008, 84:308-315.

16. Amiri $P$, Ardekani ME, Jalali-Farahani S, Hosseinpanah F, Varni JW, Ghofranipour F, Montazeri A, Azizi F: Reliability and validity of the Iranian version of the Pediatric Quality of Life Inventory 4.0 Generic Core Scales in adolescents. Qual Life Res 2010.

17. Abdel-Khalek AM: Quality of life, subjective well-being and religiosity in Muslim college students. Qual Life Res 2010.

18. Matza LS, Swensen AR, Flood EM, Secnik K, Leidy NK: Assessment of health-related quality of life in children: a review of conceptual, methodological, and regulatory issues. Value Health 2004, 7:79-92.

19. Frisen A: Measuring health-related quality of life in adolescence. Acta Paediatr 2007, 96:963-968.

20. Schlarmann JG, Metzing-Blau S, Schnep W: The use of health-related quality of life in children and adolescents as an outcome criterion to evaluate family oriented support for young carers in Germany: an integrative review of the literature. BMC Public Health 2008, 8:414.

21. Ravens-Sieberer U, Erhart M, Wille N, Wetzel R, Nickel J, Bullinger M: Generic health-related quality-of-life assessment in children and adolescents: methodological considerations. Pharmacoeconomics 2006, 24:1199-1220.

22. De Civita M, Regier D, Alamgir AH, Anis AH, Fitzgerald MJ, Marra CA: Evaluating health-related quality-of-life studies in paediatric populations: some conceptual, methodological and developmental considerations and recent applications. Pharmacoeconomics 2005, 23:659-685.

23. Coons SJ, Rao S, Keininger DL, Hays RD: A comparative review of generic quality of life instruments. Pharmacoeconomics 2000, 17:13-35.

24. Davis E, Waters E, Mackinnon A, Reddihough D, Graham HK, MehmetRadji O, Boyd R: Paediatric quality of life instruments: a review of the impact of the conceptual framework on outcomes. Dev Med Child Neurol 2006, 48:311-318.

25. Skevington SM, Lofty M, O'Connell KA: The World Health Organization's WHOQOL-Bref quality of life assessment: psychometric properties and results of the international field trial. A report from the WHOQOL group. Qual Life Res 2004, 13:299-310.

26. Leplege A, Hunt S: The problem of quality of life in medicine. JAMA 1997 , 278:47-50

27. Cummins RA: Moving from the quality of life concept to a theory. $J$ Intellectual Disability Res 2005, 49:699-706.

28. Cummins RA, Lau ALD, Stokes M: HRQOL and subjective well-being: noncomplimentary forms of outcome measurement. Expert Rev Pharmacoeconomics Outcomes Res 2004, 4:413-420.

29. Moons P, Budts W, De Geest S: Critique on the conceptualisation of quality of life: a review and evaluation of different conceptual approaches. International J Nurs Stud 2006, 43:891-901.

30. Varni JW, Burwinkle TM, Seid M, Skarr D: The PedsQL ${ }^{\mathrm{TM}} 4.0$ as a pediatric population health measure: feasibility, reliability and validity. Amb Pediatr 2003, 3:329-341.

31. Ohaeri JU, Awadalla AW, Gado OM: Subjective quality of life in a nationwide sample of Kuwaiti subjects using the short version of the WHO quality of life instrument. Soc Psychiatry Psychiatr Epidemiol 2009, 44:693-701.

32. Wille N, Bettge $\mathrm{S}$, Wittchen H-U, Ravens-Sieberger $U$, the BELLA study group: How impaired are children and adolescents by mental health problems? Results of the BELLA study. Eur Child Adolesc Psychiatry 2008, Suppl 1(17):42-51.

33. Varni JW, Burwinkle TM, Lane MM: Health-related quality of life measurement in pediatric clinical practice: an appraisal and precept for future research and application. Health Qual Outcomes 2005, 3(34).

34. Katschnig H: How useful is the concept of quality of life in psychiatry? In Quality of life in mental disorders. Edited by: Katschnig $\mathrm{H}$, Freeman $\mathrm{H}$, Sartorius N. John Wiley 2006:6 
35. Ohaeri JU, Awadalla AW, El-Abassi AH, Jacob A: Confirmatory factor analytical study of the WHOQOL-Bref: experience with Sudanese general population and psychiatric samples. BMC Med Res Methodol 2007, 7:37.

36. Ohaeri JU, Awadalla AW: The reliability and validity of the short version of the WHO Quality of Life Instrument in an Arab general population. Ann Saudi Med 2009, 29:98-104.

37. Warner R: The emics and etics of quality of life assessment. Soc Psychiatry Psychiatr Epidemiol 1999, 34:117-121.

38. Laaksonen C, Aromaa M, Heinonen OJ, Koivusilta L, Koski P, Suominen S, Vahlberg T, Salanterä S: Health related quality of life in 10-year-old schoolchildren. Qual Life Res 2008, 17:1049-1054.

39. Kiss E, Baji I, Mayer L, Skultéti D, Benák I, Vetró A: Validity and psychometric properties of a quality of life questionnaire in a Hungarian child and adolescent population. Psychiatr Hung 2007, 22:33-42.

40. Upton P, Eiser C, Cheung I, Hutchings HA, Jenney M, Maddocks A, Russell IT, Williams JG: Measurement properties of the UK-English version of the Pediatric Quality of Life Inventory 4.0 (PedsQL) generic core scales. Health Qual Life Outcomes 2005, 3:22.

41. Engelen V, Haentjens MM, Detmar SB, Koopman HM, Grootenhuis MA Health related quality of life of Dutch children: psychometric properties of the PedsQL in the Netherlands. BMC Pediatr 2009, 9:68.

42. Case A, Paxson C: Children's health and social mobility. Future Child 2006, 16:151-173.

43. Svavarsdottir EK, Orlygsdottir B: Health-related quality of life in Icelandic school children. Scand J Caring Sci 2006, 20:209-215.

44. Spurrier NJ, Sawyer MG, Clark JJ, Baghurst P: Socio-economic differentials in the health-related quality of life of Australian children: results of a national study. Aust N Z J Public Health 2003, 27:27-33.

45. Bramlett MD, Blumberg SJ: Family structure and children's physical and mental health. Health Aff (Millwood) 2007, 26:549-558.

46. Ahrons CR: Family ties after divorce: long-term implications for children Fam Process 2007, 46:53-65.

47. Zhao X, Zhang Q, Shan Y, Zhang H, Guo L: A study on the influence factors for social adaptive behavior of children. Hua Xi Yi Ke Da Xue Xue Bao 2002, 33:259-261.

48. Kauffman JM, Hallahan DP, Ball DW: Parents' predictions of their children's perceptions of family relations. J Pers Assess 1975, 39:228-235.

49. Seid M, Varni JW, Cummings L, Schonlau M: The impact of realized access to care on health-related quality of life: a two-year prospective cohort study of children in the California State Children's Health Insurance Program. J Pediatr 2006, 149:354-361.

50. King MT, Fayers PM: Making quality-of-life results more meaningful for clinicians. Lancet 2008, 371(9614):709-710.

51. Sloan JA, Frost MH, Berzon R, Dueck A, Guyatt G, Moinpour C, Sprangers M, Ferrans C, Cella D: Clinical Significance Consensus Meeting Group. The clinical significance of quality of life assessments in oncology: a summary for clinicians. Support Care Cancer 2006, 14:988-998.

52. Cummins RA: On the trail of the gold standard for subjective well-being. Soc Indicators Res 1995, 35:179-200.

53. Schwimmer JB, Burwinkle TM, Varni JM: Health-Related Quality of Life of Severely Obese Children and Adolescents. JAMA 2003, 289:1813-1819.

54. Gandek B, Ware JE: Methods for validating and norming translations of health status questionnaires: The IQOLA project approach. J Clin Epidemiol 1998, 51:953-959.

55. Graham P, Stevenson J, Flynn D: A new measure of health-related quality of life for children: preliminary findings. Psychol Health 1997, 12:655-665.

56. Olusina AK, Ohaeri JU: Subjective quality of life of recently discharged Nigerian psychiatric patients. Soc Psychiatry Psychiatr Epidemiol 2003, 38:707-714.

57. Bobak M, Pikhart H, Hertzman C, Rose R, Marmot M: Socioeconomic factors, perceived control and self-reported health in Russia. A crosssectional survey. Soc Sci Med 1998, 47:269-279.

58. Diener E: Subjective well-being: The science of happiness and a proposal for a national index. Am Psychologist 2000, 55:34-43.

59. WHO: WHOOOL User Manual. World Health Organization, Program on Mental Health, Geneva, Switzerland 1998.

60. Briere J: Trauma Symptom Checklist for Children. Florida: Psychological Assessment Resources, Inc; 1996.

61. Rosenberg M: Society and the adolescent self-image. Princeton: Princeton University Press; 1965
62. Van Steen K, Curran D, Kramer J, Molenberghs G, Van Vreckem A, Bottomley A, Sylvester R: Multicollinearity in prognostic factor analyses using the EORTC QLQ-C30: identification and impact on model selection. Statistics Med 2002, 21:3865-3884.

63. Al-Turkait FA, Ohaeri JU: Psychopathological status, behavior problems, and family adjustment of Kuwaiti children whose fathers were involved in the first gulf war. Child Adolesc Psychiatry Ment Health 2008, 2(1):12.

64. Al-Turkait FA, Ohaeri JU: Dimensional and hierarchical models of depression using the Beck Depression Inventory-II in an Arab college student sample. BMC Psychiatry 2010, 10:60

65. Abdel-Khalek AM, Lester D: Anxiety in Kuwaiti and American college students. Psychol Rep 2006, 99:512-514.

66. Abdel-Khalek AM, Lester D: Death anxiety as related to somatic symptoms in two cultures. Psychol Rep 2009, 105:409-410.

67. Kenny C: Does development make you happy?. Subjective well being in developing countries. Soc Indicators Res 2005, 73:199-219.

68. Stewart K: Dimensions of well being in EU Regions: Do GDP and unemployment tell us all we need to know? Soc Indicators Res 2005, 73:221-246.

69. El-Islam FM: Mental illness in Kuwait and Qatar. In Al-Junun Mental illness in the Islamic world. Edited by: Al-Issa I. Madison: International University Press; 2000:121-137.

70. Abdel-Khalek AM: Age and sex differences for anxiety in relation to family size, birth order, and religiosity among Kuwaiti adolescents. Psychol Rep 2002, 90(3 Pt 1):1031-6.

71. Enns MWI, Cox BJ, Clara I: Parental bonding and adult psychopathology: results from the US National comorbidity survey. Psychol Med 2002, 32:997-1008

72. George C: A representational perspective of child abuse and prevention: internal working models of attachment and caregiving. Child Abuse Negl 1996, 20:411-424.

73. Eisenberg ME, Ackard DM, Resnick MD: Protective factors and suicide risk in adolescents with a history of sexual abuse. J Ped 2007, 151:482-487

74. Supranowicz P: Parents' unemployment, selected life conditions, adolescents' well-being and perceived health. Przegl Epidemiol 2005 59:773-780.

75. "School-Wide Positive Behavioral Interventions and Supports". [http:// www.pbis.org/].

\section{Pre-publication history}

The pre-publication history for this paper can be accessed here: http://www.biomedcentral.com/1471-244X/11/71/prepub

doi:10.1186/1471-244X-11-71

Cite this article as: Al-Fayez and Ohaeri: Profile of subjective quality of life and its correlates in a nation-wide sample of high school students in an Arab setting using the WHOQOL-Bref. BMC Psychiatry 2011 11:71.

\section{Submit your next manuscript to BioMed Central and take full advantage of:}

- Convenient online submission

- Thorough peer review

- No space constraints or color figure charges

- Immediate publication on acceptance

- Inclusion in PubMed, CAS, Scopus and Google Scholar

- Research which is freely available for redistribution

Submit your manuscript at www.biomedcentral.com/submit
C Biomed Central 